\title{
EDITORIAL \\ A concerted effort to publish the best studies in neurosurgery
}

\author{
Douglas Kondziolka, MD, ${ }^{1}$ and James T. Rutka, MD, PhD² \\ ${ }^{1}$ Associate Editor, Journal of Neurosurgery Publishing Group, Charlottesville, Virginia \\ Editor-in-Chief, Journal of Neurosurgery Publishing Group, Charlottesville, Virginia
}

A

LL journals seek to collect, review, and publish high-quality science that is of value to readers. The Journal of Neurosurgery is no different. Every day we are sent reports from across the world, on a wide variety of topics that cover the full spectrum of neurosurgery. Many are of high quality. Some are not. Many provide a message that will be of value to our community. Some provide a message that would be better suited to a different readership. The observations presented may be of interest to only a highly focused subset of readers. Sometimes the findings are largely incremental, "adding to the literature," but presenting no new science.

These are some of the reasons why manuscripts are not accepted for publication in our peer-review process. All submitted manuscripts are first reviewed by the Editor-inChief (J.T.R.) or Associate Editor (D.K.). If found suitable for further review, the work is sent to the Editorial Board, from which four reviewers are chosen. As listed at the front of every issue, each journal of the Journal of Neurosurgery Publishing Group has a full-time editorial board of members who typically serve a 5- to 7-year term. A pool of ad hoc reviewers have been invited to provide additional editorial expertise. Every manuscript is scored according to the following criteria: scientific merit, neurosurgical significance, and reader interest. The manuscript is scored by each reviewer as is, and a score is also provided as an estimate upon successful revision. A final recommendation is then made to either revise or reject the manuscript. The Editor-in-Chief or Associate Editor then collates the scores from all reviews and renders a final decision, which is provided to the authors electronically.

The world of scientific publication has changed on many fronts. There are many journals; and many more appear to show up daily in our email inboxes. One might wonder if these are all legitimate journals, or are they ill conceived, and likely short-lived? There are numerous publications that touch the field of neurosurgery, either directly or indirectly. Some of these are global in scope and some more regional. But almost all can be accessed via the Internet. At the same time, publication software, submission software, and English-language software have lowered the barriers to publication. We also have "emerging markets," where authors have appeared from countries that rarely submitted 10 years ago. China is a good example. All of this may be deemed as "progress," but it does present challenges.

A good example of change is the clinical case series. Much of the history of neurosurgery is based on such reports: the outcomes after resecting 50 parasagittal meningiomas, the management of 75 patients with anterior communicating artery aneurysms, or 10 cases of moyamoya disease with a new technical nuance. Surgeons cared for patients with challenging disorders, collected their observations, and shared them. Indeed such work still remains the backbone of our literature. However, we can now use search engines to find what information exists on a topic, and the data may already be strong. In many cases, the findings are no longer "buried in the literature." So the Journal of Neurosurgery seeks not only additive science, but new science. Not just confirmatory observations, but also new observations that bring a new message.

The classification of evidence is a good way to consider your work prior to submission. Level III or IV reports, including observations and case series, are commonly submitted. Competition for their acceptance is very high. However, a clinical series that is a comparison of techniques using a formal evaluation methodology, and/ or matching of subjects to reduce bias, will have a distinct 
SUBMISSION

AUTHOR(S)

REVIEW

RE-REVIEW

FINAL DECISION \& NOTIFICATION
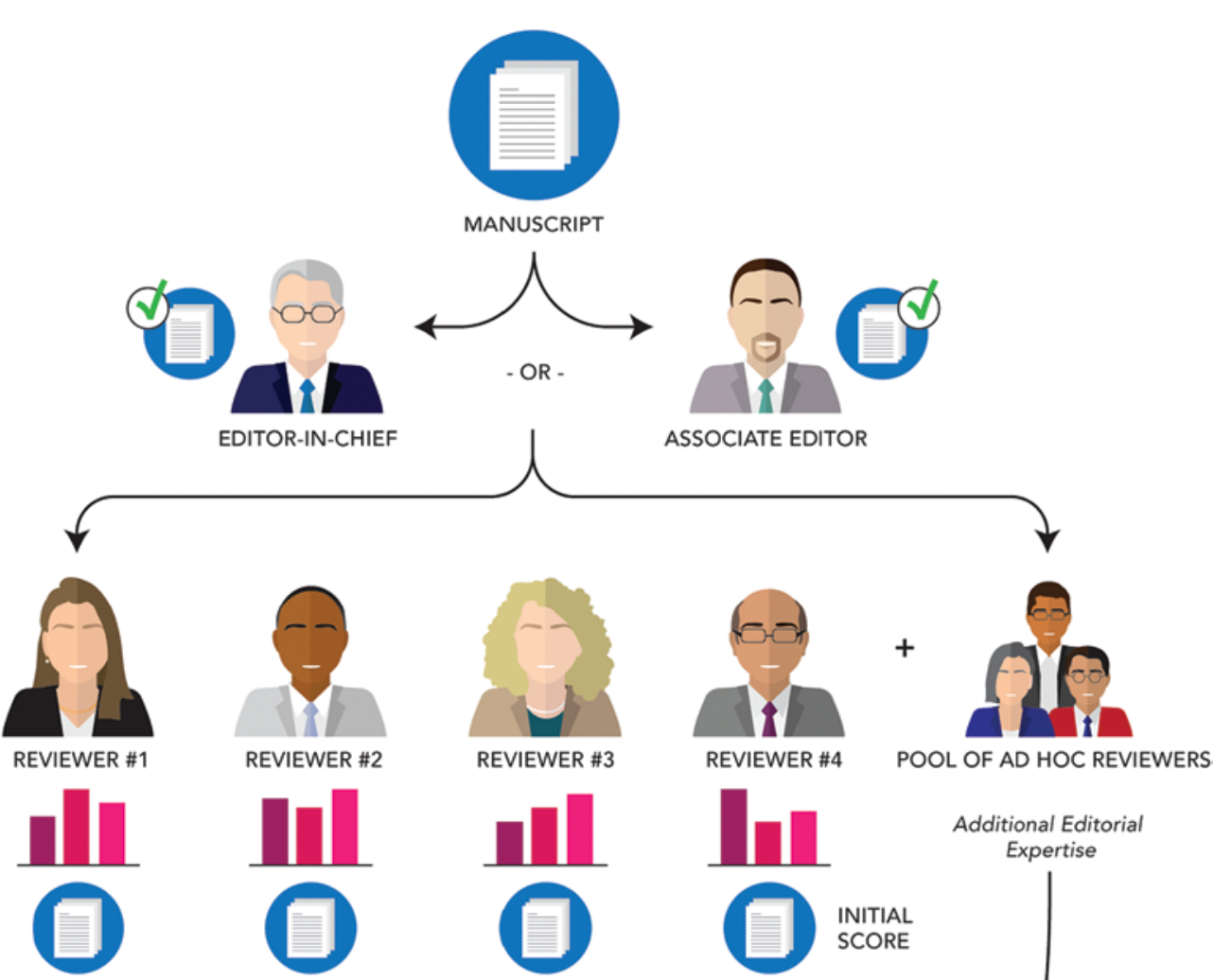

Additional Editorial

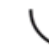

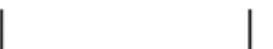

Scientific merit

Neurosurgical significance<smiles>C[14CH2]C</smiles>

REVISIONS BY AUTHOR

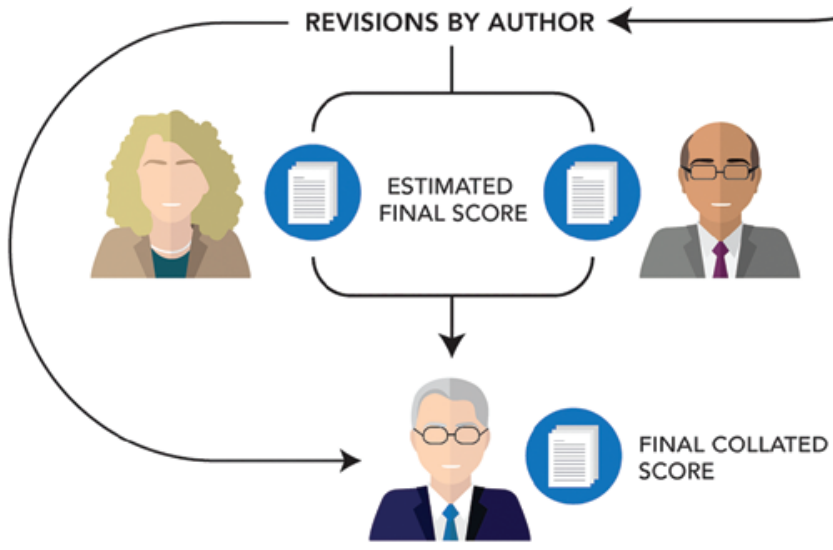

EDITOR-IN-CHIEF

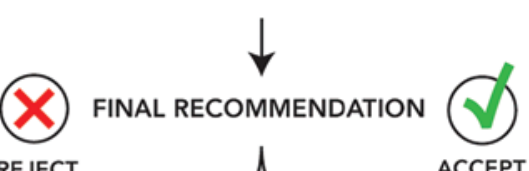

REJECT

ACCEPT

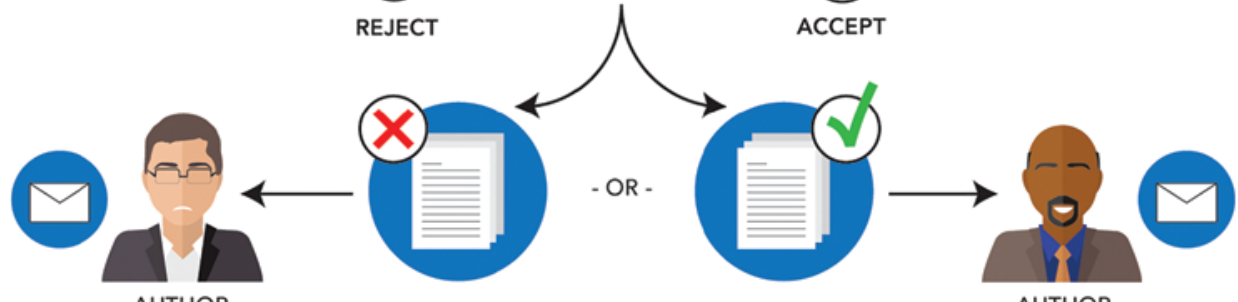

AUTHOR

AUTHOR

FIG. 1. The stages of the Journal of Neurosurgery peer-review process. Artist: Stacey Krumholtz. Figure is available in color online only. 
advantage during the evaluation process. Reports that provide new data and new insights, even if in the earlier stages of evaluation, will also be reviewed more favorably. This is not to say that every report does not have intrinsic value. We know well the time, effort, and commitment it takes to create such work. Acceptance can be a wonderful achievement, and rejection can be painful. However, the Journal of Neurosurgery represents the specialty at large. With the most edited text pages published in the field of neurosurgery, the Journal of Neurosurgery is an important archive and communication vehicle for our specialty.
With over 5000 manuscripts submitted annually, not all can be published. We seek the highest quality studies and science in our specialty. As such, give us the best that you have!

https://thejns.org/doi/abs/10.3171/2017.2.JNS17112

\section{Disclosures}

The authors report no conflict of interest. 